\title{
Thyroglobulin and Lactic Dehydrogenase Isozymes in Cystic Fluid of Thyroid Nodules
}

\author{
Mitsuo MORITA, Shiro NOGUCHI, Hitoshi KAWAMOTO, \\ JUNICHI TAJIRI*, MASAAKI TAMARU, AND NobUo MURAKAMI \\ Noguchi Thyroid Clinic and Hospital Foundation, Oita 874, and \\ *Tajiri Thyroid Clinic, Kumamoto, Japan
}

\begin{abstract}
Although fine needle aspiration biopsy (FNAB) is most valuable in the diagnosis of thyroid cancer, it is hampered by the fact that no specimen suitable for cytological examination can be collected from all cystic lesions. Often inadequate aspirates, consisting only of fluid or a few foamy cells and lacking the necessary epithelial cells, are all that an aspirationist is able to collect. Therefore an alternative method of determining the benign or malignant characteristics of cyst fluid is of vital importance. In this study we examine thyroglobulin ( $\mathrm{Tg}$ ) concentrations and lactic dehydrogenase (LDH) isozyme patterns of cyst fluid and discuss how these variables help us estimate the probability of malignancy. Fiftythree differentiated cancers (39 papillary and 14 follicular carcinomas) and 72 surgically resected benign thyroid nodules (40 adenomas, 19 colloid goiters, and 13 cysts) were analyzed. Only 28 (53\%) of 53 malignant lesions were correctly diagnosed by FNAB. The mean logarithmic value for the Tg concentration $\left(\log _{10} \mathrm{Tg}\right.$ ) was significantly lower in malignant cyst fluid than it was in benign nodules (mean $\pm \mathrm{SD}$ : $5.8 \pm 1.0$ vs. $6.8 \pm 1.0 ; P<0.001)$. The LDH 1 and 2 isozyme percentage was greater in the malignant group than in the benign group $(49.1 \pm 12.7 \%$ vs. $38.1 \pm 16.9 \% ; P<0.01)$. In multiple logistic regression analysis, $\log _{10} \mathrm{Tg}$ and the total of LDH $1+2$ percentage was significant in estimating the probability of malignant nodules. The results of our study suggest that determining the $\mathrm{Tg}$ concentration and the LDH isozyme patterns of cyst fluid could provide new information for the evaluation of cystic thyroid nodules.
\end{abstract}

Key words: Thyroid cyst, Thyroid cancer, Thyroglobulin, Lactic dehydrogenase, Fine needle aspiration biopsy.

(Endocrine Journal 41: 227-233, 1994)

MALIGNANCY was found in approximately $15 \%$ of patients operated on for cystic or partially cystic thyroid nodules [1-5]. Fine needle aspiration biopsy (FNAB) is considered very useful in distinguishing malignant and benign lesions [6-8]. However, satisfactory specimens for cytological examination cannot be collected from all cystic lesions [9-14]. Often aspirated material consists only of fluid or a few foamy cells, and the lack of epithelial cells results in an inadequate sample.

Received: July 23, 1993

Accepted: January 21, 1994

Correspondence to: Dr. Mitsuo MORITA, Noguchi Thyroid Clinic and Hospital Foundation, Noguchi Nakamachi 6-33, Beppu, Oita 874, Japan
It is known that thyroid cancer cells produce thyroglobulin (Tg) [15], but a smaller amount than that produced by normal thyroid epithelial cells or benign adenoma cells [16-19]. Therefore, if the Tg in cyst fluid is derived from epithelial cells, the Tg concentration in a malignant cyst should be lower than that in a benign cyst. Sometimes the aspirated fluid is dark brownish or of a bloody color. If a malignant lesion is inclined to bleed into a cystic space, the lactic dehydrogenase (LDH) isozymes assume a 'hemolytic pattern' [20].

Since it is relatively easy to collect fluid from cystic nodules and to analyze the biochemical features of these fluids, we measured the $\mathrm{Tg}$ concentration and determined the LDH isozyme pattern of cyst fluid in 125 patients. 


\section{Materials and Methods}

\section{Patients}

From January, 1986 to December, 1989, 670 patients were operated on at Noguchi Thyroid Clinic for differentiated thyroid carcinomas larger than 1 $\mathrm{cm}$ in diameter. Among these cases, 55 lesions (8.2\%) were partially or fully cystic (i.e. more than $0.5 \mathrm{ml}$ of fluid was aspirated). Two patients who had previously experienced FNAB in another hospital were excluded from this study. Fifty-three cases of differentiated carcinoma (39 papillary carcinoma and 14 follicular carcinoma) were analyzed.

In the same period, patients having benign thyroid nodules that were purely or partially cystic also underwent FNAB. Among these patients, only those who had been operated on were selected. The sample was excluded from the study if the patient had already undergone FNAB, if a concomitant malignant lesion existed, or if the sample was to gluey to determine the LDH isozyme. Seventytwo operated patients were eventually chosen and analyzed. Histological findings for these 72 lesions revealed 40 adenomata, 19 colloid goiters, and 13 cysts.

\section{Methods}

\section{1) FNAB and cytology}

FNAB was performed with a 22-gauge needle attached to a $5-\mathrm{m} l$ syringe. All specimens were reviewed by one screener, and classified according to the criteria reported by Ramacciotti et al. [8]: benign, class 1 or class 2 (in brief, normalappearing follicular cells or mild-to-moderate atypia with findings indicative of inflammation); malignant, class 4 or class 5 (atypical papillary structures with psamomma bodies, or many noncohesive follicular cells with marked-to-severe atypia); indeterminate, class 3 (occasional follicular cells with moderate-to-marked atypia); and insufficient, class 0 (insufficient materials for cytologic interpretation). Aspirations were repeated in 42 cases where the specimens were class 0 or during follow-up of patients with benign cytologic results. In these cases, the highest class of cytologic diagnosis was adopted.

\section{2) Tg assay}

$\mathrm{Tg}$ concentrations of aspirated material and serum were determined by one-step enzyme immunoassay (EIA) as previously reported [21]. Two different anti-Tg monoclonal antibodies (monoAb) were obtained from Balb/c mice immunized with human Tg. Samples or standard solutions $(50 \mu l)$ and monoAb-peroxidase conjugates $(150 \mu l)$ were added simultaneously to microplates covered with another monoAb. Each plate was incubated for 60 min and then washed. After adding $100 \mu l$ of peroxidase substrate, the plate was incubated for 30 min, at which point the reaction was stopped and the optical density of each well was determined. The serum $\mathrm{Tg}$ values obtained from 41 normal subjects showed logarithmic distribution ranging from 0 to $55 \mathrm{ng} / \mathrm{ml}$.

3) Total LDH activity and LDH isozyme assay

The total LDH activity and LDH isozyme patterns were determined with commercially available assay kits (LDH Test "KATAYAMA", KATAYAMA KAGAKU Inc., Japan and LDH Isozyme Test "WAKO", Wako Junyaku Inc., Japan).

4) Statistical analysis.

Statistical analysis was performed by means of the SAS system (SAS Institute Inc., USA). The values for Tg concentrations and LDH activity were $\log _{10}$-transformed. For the 125 analyzed cases, a multiple logistic model was applied to estimate the probability of malignancy. The logarithmic value for the $\mathrm{Tg}$ concentration $\left(\log _{10} \mathrm{Tg}\right)$ and the total proportion of $\mathrm{LDH}$ isozyme $1+2$ were used as the explanatory variables. The parameters were estimated by means of the LOGISTIC Procedure (SAS Release 6.04) [22].

\section{Results}

There was no significant difference between the malignant and benign groups as to age (mean \pm SD, $48 \pm 13$ vs. $47 \pm 14: P=0.68$, Student's $t$-test), sex (male/female, $10 / 43$ vs. $7 / 65 ; P=0.14$, chi-square test) or the mean logarithmic value for the serum Tg level ( $2.2 \pm 0.82$ vs. $2.19 \pm 0.85 ; P=0.95$, Student's $t$-test). FNAB findings for the 53 thyroid carcinomas were 18 (34\%) with malignant, 10 (19\%) with indeterminate, 7 (13\%) with benign and 18 (34\%) with insufficient specimens. Sensitivity calculated as (indeterminate + malignant/benign + indetermi- 
nate + malignant) was $80 \%$. In 18 patients (34\%), however, aspirated material was not diagnosed because the specimens contained only foamy cells and/or red blood corpuscles. Ultimately, only 28 (53\%) of 53 malignant lesions were correctly diagnosed by FNAB.

The characteristics of cyst fluid in both the benign and malignant groups are summarized in Table 1. The mean $\log _{10} \mathrm{Tg}$ was significantly lower in malignant nodules $(5.8 \pm 1.0$ vs. $6.8 \pm 1.0$; $P<0.001) . \log _{10} \mathrm{Tg}$ values were lower than 5.0 in $23 \%$ of the malignant group and $4 \%$ of the benign group (Fig. 1). Mean logarithmic total LDH activity was also lower in malignant cyst fluid (3.09 \pm 0.49 vs. $3.49 \pm 0.45 ; P<0.001$ ). However, the proportion of LDH isozymes 1 and 2 was greater in the malignant group than in the benign group $(49.1 \pm 12.7$ vs. $38.1 \pm 16.9 ; P<0.01)$. The total proportion of LDH 1 and 2 was higher than or equal to $50 \%$ in $51 \%(27 / 53)$ of the malignant group and $25 \%(18 /$ 72) of the benign group (Fig. 2).

Logistic analysis indicated that the Tg concentration had a significant negative relation with the expected odds for (probability that a nodule is malignant)/(probability that a nodule is benign), and the total proportion of $\mathrm{LDH} 1+2$ had a significant positive relation with the expected odds (see footnote for details). The 10 times increase in the $\mathrm{Tg}$ concentration reduces the expected odds by $61 \%$. The $10 \%$ increase in the total proportion of LDH1

Table 1. Comparison of cyst fluid characteristics in malignant and benign groups

\begin{tabular}{lccccccc}
\hline & Log Tg & Log LDH & LDH1 & LDH2 & LDH3 & LDH4 & LDH5 \\
\hline $\begin{array}{c}\text { Malignant nodules } \\
(n=53)\end{array}$ & $5.80 \pm 1.05$ & $3.09 \pm 0.49$ & $20.3 \pm 6.5$ & $28.8 \pm 8.5$ & $18.3 \pm 4.0$ & $14.6 \pm 7.0$ & $18.0 \pm 9.7$ \\
$\begin{array}{c}\text { Benign nodules } \\
(n=72)\end{array}$ & $6.81 \pm 1.00$ & $3.49 \pm 0.45$ & $16.0 \pm 10.4$ & $22.1 \pm 8.3$ & $18.1 \pm 3.8$ & $18.9 \pm 6.9$ & $25.2 \pm 11.8$ \\
& $P<0.001$ & $P<0.001$ & $P<0.01$ & $P<0.001$ & $P=0.776$ & $P<0.001$ & $P<0.001$ \\
\hline
\end{tabular}

$\log \mathrm{Tg}$ represents the logarithmic value for the thyroglobulin concentration $(\mathrm{ng} / \mathrm{ml})$; Log LDH, the logarithmic value for total lactic dehydrogenase activity (IU/L); LDH1, lactic dehydrogenase isozyme 1. Values are expressed as the mean $\pm \mathrm{SD}$.

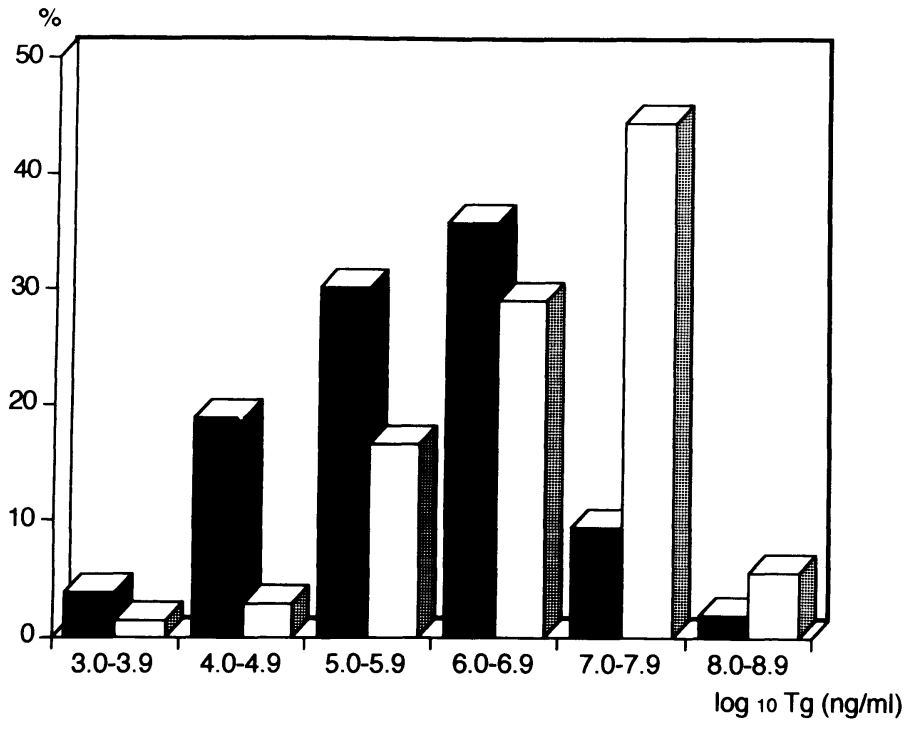

Fig. 1. Distribution of thyroglobulin (Tg) concentration in cyst fluid from malignant (solid bars) and benign (open bars) nodules. $\mathrm{X}$-axis indicates the category of logarithmic value for the $\mathrm{Tg}$ concentration $\left[\log _{10}(\mathrm{ng} / \mathrm{m} l)\right]$. 
+2 increases the odds by $57 \%$. Figure 3 illustrates the observed joint distribution of the $\mathrm{Tg}$ concentration and the total proportion of LDH1 +2 for malignant and benign nodules. The lines indicate that the estimated probabilities of malignancy are 0.2 and 0.8. In the upper left area above the upper line, the probability of malignancy is lower than 0.2 . In the lower right area below the lower line, the probability of malignancy is higher than 0.8 . Figure 4 shows the joint distribution of $\mathrm{Tg}$ and $\mathrm{LDH} 1+2$ for

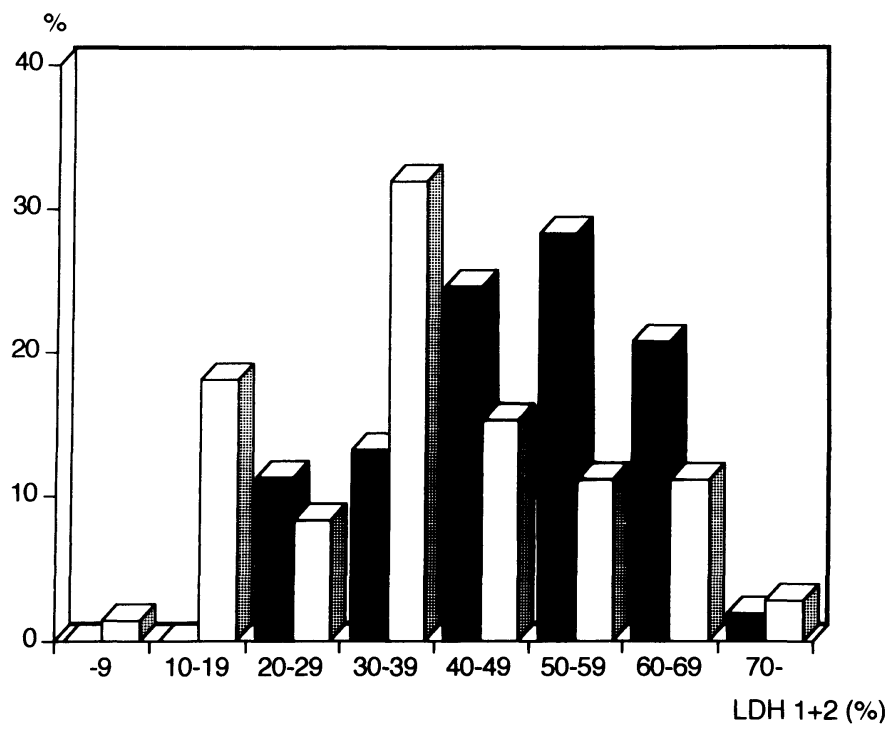

Fig. 2. Distribution of the total percentage of lactic dehydrogenase isozymes 1 and 2 in cyst fluid from malignant (solid bars) and benign (open bars) nodules. $\mathrm{X}$-axis indicates the category of sum totals of isozyme 1 and isozyme $2(\%)$.

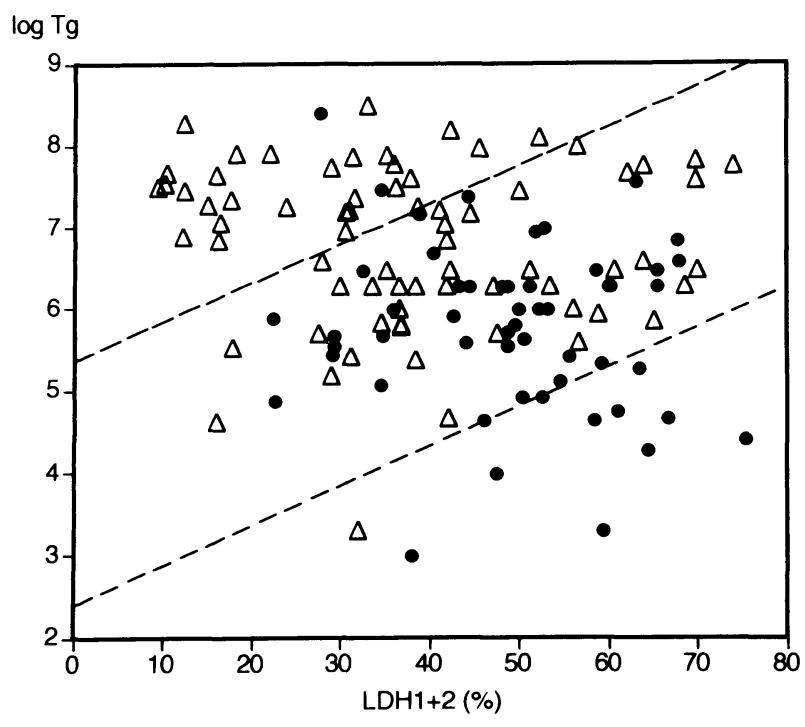

Fig. 3. Joint distribution of the Tg concentration and total proportion of LDH isozyme $1+2$ in cyst fluid from malignant (solid circles) and benign (open triangles) nodules. The probability of malignancy calculated by a multiple logistic model. The probability of 0.2 is shown by the upper broken line, and 0.8 by the lower broken line.

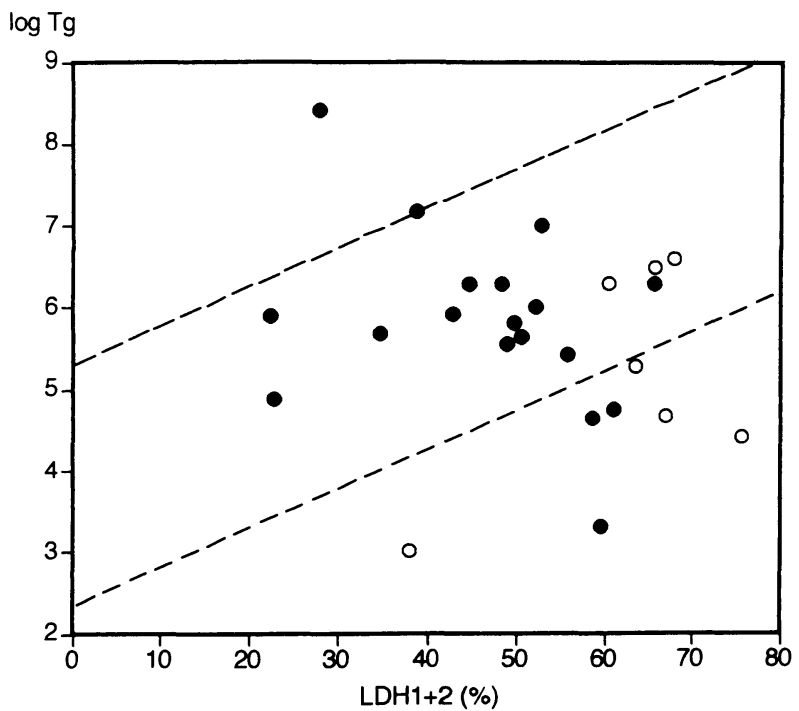

Fig. 4. Joint distribution of malignant nodules with false negative findings in fine needle aspiration biopsy (FNAB). Open circles represent 'benign' and solid circles represent 'insufficient'. Other details are the same as in Fig. 3. 
malignant nodules which were not correctly diagnosed in FNAB. The mean estimated probability of malignancy in 'benign' cytology (open circles) was $78 \%$, and the mean in a 'insufficient' specimen (solid circles) was $55 \%$.

\section{Discussion}

There have been widely divergent reports as to the proportion of carcinoma to cystic nodules in thyroid glands. In early studies, the figures were considerably low. Crile treated 58 thyroid cysts by aspiration, and he emphasized that almost all of the hemorrhagic or colloid cysts were benign [23] In a detailed review by Ashcraft and van Herle [6], a mere 21 carcinomas $(0.9 \%)$ were found in 2290 cystic nodules that included both pure and mix lesions. Recently, however, relatively high rates of malignancy have been reported, such as the 16 cases $(17 \%)$ of malignancy found in 94 operated cases by Dr. M. Hammer [2], 19 cases (32\%) among 60 operated cases by Dr. I. B. Rosen [13]. De los Santos and coworkers [4] reported in their retrospective study of resected thyroid nodules, that the incidence of malignancy in cystic lesions was as high as in solitary lesions ( $14 \%$ to $23 \%$ ). Among approximately 1300 cysts aspirated for our study, 53 nodules $(4.1 \%)$ were thyroid carcinomas. This figure is about 4.5 times greater than that in Ashcraft's review.

The development of fine needle aspiration biopsy (FNAB) has been most helpful in differentiating malignant and benign lesions [6-8]. However, there is a serious limitation in that. Specimens sufficient for diagnosis cannot always be collected from cystic lesions. Often aspirated materials consist only of fluid and lack epithelial cells [9-14]. One might expect that ultrasonographically guided FNAB with a high-resolution, real-time scanner would be useful in some cases of solid tumors projecting into cystic lesions [10]. Yet this method may be somewhat cumbersome and time consuming.

There has been limited discussion about the biochemical features of cyst fluid. Clark et al. measured the thyroid hormone and $\mathrm{Tg}$ concentrations in cystic neck masses [24]. They concluded that hormonal analysis of cyst fluid was sometimes helpful in predicting the origin of cysts such as parathyroid cysts, or thyroglossal duct cysts.
DeGroot and Carvalho reported that malignant thyroid tumors contained less $\mathrm{Tg}$ than benign tumors [16]. Several authors reported similar results $[18,19]$. Bearing these facts in mind, if $\mathrm{Tg}$ in cyst fluid was produced by the epithelial cells or derived from degenerated tumor cells, the Tg concentrations aspirated from malignant cysts should be lower than in benign cysts. In 1984, Kawamura et al. pointed out that $\mathrm{Tg}$ levels in papillary cancer fluids were lower than those in follicular adenoma fluids [15]. Yet their report was based on only a few cases. Recent advances in molecular biology revealed that thyroid cancer cells express Tg messenger ribonucleic acid (mRNA) [26], and that levels of $\mathrm{Tg}$ mRNA are significantly lowered in adenoma and carcinoma tissues as compared to normal tissues [27, 28]. Moreover, moderately differentiated cancer cells contain less Tg mRNA than well-differentiated cancer cells [26]. Although an abnormal serum thyrotropin level may affect $\mathrm{Tg}$ production, most patients in our study had not undergone thyroxine therapy that might reduce $\mathrm{Tg}$ production through suppression of the intrinsic thyrotropin level. Most patients had no thyroid autoantibody, and no patient had concomitant Graves' disease. Our results, therefore, support the assumption that the difference between malignant and benign cysts in $\mathrm{Tg}$ concentrations may result from the inherent disparity of $\mathrm{Tg}$ production.

It sometimes occurs that aspirated fluid is dark brownish or of a bloody color [29]. Ashcraft and van Herle reviewed the correlation between the cyst fluid color and the possibility of cancer [6], and reiterated Mazaferri's opinion that bloody fluid should lead one to be concerned about a possible solid-cystic papillary cancer. An intravascular hemolytic condition such as hemolytic anemia or nocturnal hemoglobinuria, demonstrates an absolute increase in LDH1 and LDH2 [20]. If the malignant thyroid nodule tended to blood into the cystic space, then the LDH isozyme of the cyst fluid could present a 'hemolytic pattern', i.e., an increase of LDH1 and LDH2, whereas the LDH isozyme composition of watery extracts of normal human thyroid is LDH 3-5 predominant [30].

In the logistic regression analysis, both variables- $\log _{10} \mathrm{Tg}$ and total proportion of LDH1 + 2had regression coefficients significantly different from $0(P<0.01)$. The combination of these two variables gave a better estimation of the probability of malignancy than either $\log _{10} \mathrm{Tg}$ or LDH1 +2 
did alone.

In conclusion, analysis of the biochemical features of cystic fluid is relatively easy because fluid can be collected from almost all cystic nodules. The results of our study suggest that the Tg concentrations and LDH isozyme patterns could be helpful variables for the management of cystic thyroid nodules. Physicians should heed the possibility of malignancy when the cyst fluid shows low Tg concentrations and high proportions of LDH1 +2 .

Footnote: The logit of probability $(p)$ that a nodule is malignant was expressed by the multiple regression equation, $\operatorname{logit}(p)=\log (p / q)=a+b x+c y$, where $q(=1-p)$ is the probability that a nodule is benign, $x$ is $\log _{10}$ of the $T g$ concentration $(\mathrm{ng} / \mathrm{ml})$, $\mathrm{y}$ is the total $\mathrm{LDH} 1+2$ percentage, and $\mathrm{a}$ is the intercept and $b$ and $c$ are the coefficients. The pa- rameter estimates and standard errors were $a=3.6546 \pm 1.5293, b=-0.9419 \pm 0.2289$, and $c=0.0451 \pm 0.0147$. The log odds ratio for the increase in $x$ due to $\Delta x$ is $\log (p / q)_{x}=x+\Delta x-\log (p / q)$ $\mathrm{x}=\mathrm{x}=(\mathrm{a}+\mathrm{b}(\mathrm{X}+\Delta \mathrm{x})+\mathrm{cy})-(\mathrm{a}+\mathrm{bX}+\mathrm{cy})=\mathrm{b} \Delta \mathrm{x}$. Then the odds ratio is $(p / q)_{x=x+\Delta x} /(p / q){ }_{x=x}=$ $\exp (b \Delta x)$. The 10 times increase in $\mathrm{Tg}$ which is equivalent to $\Delta x=1$ yields an odds ratio of $\exp (-$ $0.9419)=0.39$. Similarly, the $10 \%$ increase in LDH1 +2 which is equivalent to $\Delta y=10$ yields an odds ratio of $\exp (\mathrm{c} \Delta \mathrm{y})=\exp (0.0451 \times 10)=1.57$

\section{Acknowledgment}

We thank Ms. Linda Kawabata for reading and correcting the manuscript.

\section{References}

1. Ashcraft MW, Van Herle AJ (1981) Management of thyroid nodules: I. Head Neck Surg 3: 216-230.

2. Hammer M, Worstman J, Folse R (1982) Cancer in cystic lesions of the thyroid. Arc Surg 117: 10201023.

3. Rojeski MT, Gharib H (1985) Nodular thyroid disease. New Engl J Med 313: 428-436.

4. De los Santos ET, Keyhani-Rofagha S, Cunningham JJ, Mazzaferri EL (1990) Cystic thyroid nodules: The dilemma of malignant lesions. Arch Intern Med 150: 1422-1427.

5. Cusick EL, Mclntosh CA, Krukowski ZH, Matheson NA (1988) Cystic change and neoplasia in isolated thyroid swellings. Br J Surg 75: 982983.

6. Ashcraft MW, Van Herle AJ (1981) Management of thyroid nodules: II. Head Neck Surg 3: 297-322.

7. Mazzaferri EL, De los Santos ET, Keyhani-Rofagha $S$ (1988) Solitary thyroid nodule: diagnosis and management. Med Clin North Am 72: 1177-1211.

8. Ramacciotti CE, Pretorius HT, Chu EW, Barsky SH, Brennan MF, Robbins J (1984) Diagnostic accuracy and use of aspiration biopsy in the management of thyroid nodules. Arch Intern Med 144: 1169-1173.

9. Goellner JR, Johnson DA (1982) Cytology of cystic papillary carcinoma of the thyroid. Acta Cytol 26: 797-799.

10. Müller N, Cooperbrg PL, Suen $\mathrm{KCH}$, Thorson SC (1985) Needle aspiration biopsy in cystic papillary carcinoma of the thyroid. AJR 144: 251-253.

11. Boey J, Hsu C, Collins RJ (1986) False-negative errors in fine-needle aspiration biopsy of dominant thyroid nodules. World J Surg 10: 623-630.

12. Sarda AK, Bal S, Dutta Gupta S, Kapur MM (1988) Diagnosis and treatment of cystic disease of the thyroid by aspiration. Surgery 103: 593-596.

13. Rosen IB, Provias JP, Walfish PG (1986) Pathologic nature of cystic thyroid nodules selected for surgery by needle aspiration biopsy. Surgery 100: 606-612.

14. Hsu C, Boey J (1987) Diagnostic pitfalls in the fine needle aspiration of thyroid nodules. Acta Cytol 31: 699-704.

15. Gerfo PL, Volsi VL, Colacchio D, Feind C (1978) Thyroglobulin production by thyroid cancers. $J$ Surg Res 24: 1-6.

16. DeGroot LJ, Carvalho E (1960) Studies on proteins of normal and diseased thyroid glands. J Clin Endocr 20: 21-34.

17. Thomas-Morvan C, Nataf B, Tubiana M (1974) Thyroid proteins and hormone synthesis in human thyroid cancer. Acta Endocrinol 76: 651-669.

18. Valenta L, Lemarchand-Beraud (1970) Thyroglobulin and thyroid acid protease activity in thyroid disease. J Clin Endocr 31: 422-427.

19. Valenta L, Kyncl F, Niederle B, Jirousek L (1986) Soluble proteins in thyroid neoplasia. L Clin Endocr 28: 442-450.

20. Wright EJ, Cawley LP and Eberhardt L (1966) Clinical application and interpretation of the serum lactic dehydrogenase zymogram. Am J Clin Path 45(6): 737-745.

21. Kato R, Noguchi S, Noguchi A (1987) Human serum thyroglobulin determination with monoclonal 
antibody one-step assay. Endocrinol Japon 34: 171178.

22. SAS Institute Inc (1990) SAS Technical Report P200, SAS/STAT Software: CALIS and LOGISTIC Procedures, Release 6.04, Cary, NC; SAS Institute Inc., 236 pp.

23. Crile $G$ (1966) Treatment of thyroid cysts by aspiration. Surgery 59: 210-212.

24. Clark OH, Okerlund MD, Cavalieri RR, Greenspan FS (1979) Diagnosis and treatment of thyroid, parathyroid, and thyroglossal duct cysts. J Clin Endocrinol Metab 48: 983-988.

25. Kawamura S, Kishino B, Miyauchi A, Takai S, Tajima M, Mashita K, et al. (1984) The differential diagnosis of cystic neck masses by the determination of thyroglobulin concentration in the aspirates. Clin Endocrinol 20: 261-267.

26. Berge-Lefranc J-L, Cartouzou G, De Micco C, Fragu
P, Lissitzky S (1985) Quantification of thyroglobulin messenger RNA by in situ hybridization in differentiated thyroid cancers. Cancer 56: 345-350.

27. Rossi P, Uberti ED, Trasforini G, Barbieri R, Piva R, Gambari R (1986) Different levels of thyroglobulin mRNA in normal and neoplastic human thyroids. Cell Biol Int Rep 10: 588.

28. Ohta K, Endo T, Onaya T (1991) The mRNA levels of thyrotropin receptor, thyroglobulin and thyroid peroxidase in neoplastic human thyroid tissues. Biochem Biophys Res Commun 174: 1148-1153.

29. Ma MKG, Ong GB (1975) Cystic thyroid nodules. Br J Surg 62: 205-206.

30. Wroblewski F, Gregory KF (1961) Lactic dehydrogenase isozymes and their distribution in normal tissues and plasma and in disease states. Ann NY Acad Sci 95: 912-932. 